\title{
Price elasticity of demand for psychiatric consultation in a Nigerian psychiatric service.
}

\author{
Oluyomi Esan
}

Department of Psychiatry, University of Ibadan, University College Hospital, PMB 5116, Ibadan, Nigeria.

\begin{abstract}
:
Objective: This paper addresses price elasticity of demand (PED) in a region where most patients make payments for consultations out of pocket. PED is a measure of the responsiveness of the quantity demanded of goods or services to changes in price. The study was done in the context of an outpatient psychiatric clinic in a sub -Saharan African country.

Methods: The study was performed at the University College Hospital (UCH), Ibadan, Nigeria. Aggregate data were collected on weekly clinic attendance over a 24- month period October 2008 - September 2010 representing 12 months before, to 12 months after a $67 \%$ increase in price of outpatient psychiatric consultation. The average weekly clinic attendance prior to the increase was compared to the average clinic attendance after the price increase. Arc-PED for consultation was also estimated.

Results: Clinic attendance dropped immediately and significantly in the weeks following the price increase. There was a $34.4 \%$ reduction in average weekly clinic attendance. Arc-PED for psychiatric consultation was -0.85 .

Conclusion: In comparison to reported PED on health care goods and services, this study finds a relatively high PED in psychiatric consultation following an increase in price of user fees of psychiatric consultation.

Keywords: Price Elasticity of Demand (PED), outpatient psychiatric clinic, Nigerian.

DOI: http://dx.doi.org/10.4314/ahs.v16i4.18

Cite as: Oluyomi E. Price elasticity of demand for psychiatric consultation in a Nigerian psychiatric service. Afri Health Sci2016;16(4): 10181022. bttp://dx.doi.org/10.4314/abs.v16i4.18
\end{abstract}

\section{Background}

One tool extensively used by Health Economists in the field of health or Medicine to assess the impact of price changes on utilization of health services is the Price Elasticity of Demand (PED).

It is defined as the rate of change in demand that accompanies a change in price. It measures the responsiveness of the quantity demanded of a good or service to changes in price. PED quantifies how much demand falls for every percentage increase in the price of a good or service. There are two alternative measures of PED. Point-PED which measures the elasticity of demand at a particular point on a demand curve and Arc-PED which measures elasticity at the midpoint between the two selected points ${ }^{1}$.Because at higher prices, the quantity of goods / services demanded will be less, PED appears as a negative number. Elasticity larger than - 1.0 means a

\section{Corresponding author:}

Oluyomi Esan,

Department of Psychiatry, University of Ibadan, Uni-

versity College Hospital, PMB 5116,

Ibadan, Nigeria.

Tel: +2348033880312

Email: oluyomie@yahoo.com change in price has a relatively large impact on demand. This is interpreted as elastic. If the elasticity is between zero and -1.0 , this is interpreted as a inelastic demand. This means that the percentage change in demand is smaller than the percentage change in price. For goods or services that are absolute necessities price changes have very little or no impact on the quantity demanded. For example the demand for emergency health services such as defibrillator at times of cardiac arrest will be relatively inelastic. However, for luxury goods and services (for example, luxury cars, going on a boat cruise etc.) demand is highly price-elastic. Accordingly, such commodities have high elasticity of demand. Demand for health care is generally priceinelastic, with PED estimates normally hovering around $-0.2 .^{2,3}$, and between -0.1 to -0.6 for prescription drugs ${ }^{2}$.

In low- and middle-income countries removing or reducing user fees have been found to increase the utilization of curative and preventive health services. Similarly introducing or increasing user fees reduce the utilization of some curative services, although quality improvements may help maintain utilization ${ }^{4}$.

Consumers, in general, adapt to changes in price not only by changing the quantity purchased, but also by changing the quality. There is disparity in consumer response 
to health service utilization depending on whether they are public or private. For example, a study from Lesothoshowed that increasing user fees led to a drop in utilization in the public sector, while for the same increase the uptake of services in private not-for-profit facilities did not change ${ }^{5}$

Financing health care through user fees have certain characteristics: (a) Payment is made at the point of service use (b) There is no risk sharing. (c) It may present a barrier to access (d) it may have negative effects on equity ${ }^{6-8}$. Despite the aforementioned issues, in Nigeria (as well as in many sub-Saharan countries) over $60 \%$ of health expenditure comes from out of pocket payment ${ }^{9}$.

In September 2009, the cost of user fees at the University College Hospital (UCH) Ibadan, Nigeria was reviewed upwards. The price of consultation at theoutpatient clinic was increased from 750 Naira (\$6) to 1, 250Naira (\$8.33), a $67 \%$ increase. We hypothesized that the increase would have a negative impact on demand for consultation.

The aim of this study was to determine the magnitude of the effect of this price increase on demand for psychiatric consultation (i.e. Health service utilization) and estimate Arc-PED for psychiatric consultation following this increase.

\section{Methods}

The study was descriptive and observational. The ob-

\section{Results}

Table 1 shows the weekly mean clinic attendance over the 24-month period. The highest clinic attendance, 152, was in April 2009 while the lowest was 60 in September 2010.The highest clinic attendance after the increase was in January 2010 where clinic attendance was 109. servations resulted from a "natural experiment" and involved examining utilization before and after a $67 \%$ price increase for consultation services. The study was performed at University College Hospital (UCH), Ibadan Nigeria. UCH is an academic tertiary care teaching hospital and referral center. It is located in Ibadan, Southwest Nigeria. The hospital receives referrals from Southwest Nigeria and not

infrequently from other parts of Nigeria. The estimated population of South West Nigeria is about 28 million. ${ }^{10}$

The Department of Psychiatry is one of the major specialties in the hospital. The hospital runs two adult clinics on Mondays and Fridays. The records officer for each clinic records the clinic attendance. An inventory of the weekly clinic attendance 12 months before the increase in price of consultation to 12 months after the increase was taken. Aggregate data on clinic attendance was collected to capture the 24-month period (October 2008 -September 2010). The effect of price increase was measured in terms of changes in service utilization (clinic attendance) and Arc-PED. The study was conducted in compliance with recognized international standards, including the International Conference on Harmonization, the Council for International Organizations of Medical Sciences and the principles of the Declaration of Helsinki.

The weekly mean clinic attendance before the consultation fee was increased was 128.5 (S.D. $=15.3$ ) while the mean weekly clinic attendance after the increase was 84.3 (S.D. =15.9). The decrease in mean clinic attendance of 44.2 was statistically significant $\mathrm{P}<0.001$ (95\% CI 34.553.9.) This reduction represents a $34.4 \%$ reduction in weekly clinic attendance. The price elasticity of demand was -0.85 . 
Table 1:

\begin{tabular}{llll}
\hline $\begin{array}{l}\text { 12 months before increase } \\
\text { (October 2008-September }\end{array}$ & Attendance & $\begin{array}{l}12 \text { months after } \\
\text { increase (October } \\
\text { 2009-September } \\
\text { 2010) }\end{array}$ & Attendance \\
\hline October 2008 & & October 2009 & 107 \\
November2008 & 131 & November 2009 & 95 \\
December 2008 & 125 & December 2009 & 89 \\
January 2009 & 141 & January 2010 & 109 \\
February 2009 & 111 & February 2010 & 67 \\
March 2009 & 113 & March 2010 & 93 \\
April 2009 & 126 & April 2010 & 69 \\
May 2009 & 152 & May 2010 & 95 \\
June 2009 & 141 & June 2010 & 73 \\
July 2009 & 145 & July 2010 & 78 \\
August 2009 & 99 & August 2010 & 77 \\
September 2009 & 128 & September 2010 & 60 \\
\hline Mean for the Year & 130 & & $\mathbf{8 4 . 3}$ \\
\hline
\end{tabular}

\section{Discussion}

This study provides evidence that there was a significant decrease in demand for psychiatric consultation (weekly clinic attendance) from 128.5 per week to 84.3 per week following the price hike. The Arc-PED for psychiatric consultation was -0.85 . The significance of a PED for consultation of -0.85 can be better appreciated when one considers that estimates of price elasticity for hospital care ranges from -0.14 to $-0.2^{2,3,11}$. The figure -0.14 to -0.2 suggests that demand for hospital care/health services is highly inelastic, meaning that when people need curative care or other health services, especially at times of life-threatening illnesses or injury, they are far less likely to be concerned about the price of the service. They usually find any means possible to pay. In Nigeria, it is not uncommon for patients and their relatives to sell landed property, houses, cars and shares to offset medical bills. By strict definition, a PED of -0.85 should be classified as inelastic, but considering that the PED for health care products ranges from- 0.14 to -0.2 , a PED of health care product in the range of -0.85 is high. What was found in the current study (-0.85) is 4-6 times the PED for health care in general.

What do the findings of this study suggest? It implies that the decision to increase consultation fees by $66.7 \%$ has negatively impacted the number of hospital visits by $34.4 \%$. Count of hospital visits per month differs from the count of patients visiting the hospital per month, given that a single patient may make more than one visit to the hospital in a month, as prescribed by the doctor. Consequently, since we did not obtain weekly visits per patient, before and after the price increase, we could not assess the impact of price change on the number of patients visiting the hospital as we have done for the impact on the number of consultations.

Nevertheless, the few of our patients who visit the outpatient clinic more than once a month are those that need more frequent assessments because of the severity of their illness. This means that a substantial proportion of the decrease in hospital visits was in fact due to a decrease in the number of patients visiting the clinic. The consequence of this is that those unwilling to pay the higher prices (who in many cases are patients' relatives) probably cannot afford to do so, or have stronger, competing priorities for their money. Those still willing to pay the higher prices probably do so because they can afford to pay, and attach a higher value to health consultations for themselves or their relatives as the case may be, albeit at an opportunity cost.

In Nigeria, a middle income country (as classified by the World Bank), over $52 \%$ of the population earns below the minimum wage of 18000 Naira (106USD), and over $60 \%$ of the population lives below the poverty line ${ }^{12}$. Based on the observations from this clinic, how do patients / patient relatives adjust to such increases in prices? First, patients may not pay for consultation, even if they are willing, because the services are beyond their capacity to pay. As such, they remain at home with their illnesses. The results are relapses, morbidities and in worse cases mortalities, all of which could have been prevented. Furthermore, since out of pocket payments (unlike public or 
private health insurance schemes) do not protect patients from the costs of illness, the increase has substantial negative effects and may lead to increasing poverty and suffering for the patients or their relatives. This situation is worsened by the fact that people with low socio-economic status are more susceptible to mental disorders and vice versa ${ }^{13,14}$. Such mental disorders are associated with reduced earnings ${ }^{15}$. Consequently, those that attempt to pay lose what little money or assets they have. Alternatively, if they do not pay and get treated, the mental illness worsens. What is then created is a vicious cycle of poverty and mental illness. Secondly, patients may adjust to a price increase by reducing the number of follow up visits to affordable limits. For example, if prescribed follow up visits are 1 per month, with a price hike, a patient may reduce this to 1 in 4 months, 1 in 6 months or even less frequently depending on the affordability. Thirdly, patients may make adjustments to price change by changing the quality of care to cheaper alternatives. In mental health care, this comes in the form of complementary alternative mental health care providers such as herbalists, spiritualists, churches etc. Unfortunately, anecdotal reports show that many patients cumulatively end up paying more with some of the complementary alternative mental health care providers.

While the need to cover running costs in hospitals by generating more funds is important, there are other ways in which the financial burden of the cost of health care can be reduced. One method is by increased risk pooling. Risk pooling is the management of financial resources so that large, unpredictable individual financial risks become predictable and are distributed among all members of the pool. The pooling of financial risks is the foundation of traditional health insurance schemes. Examples include the National Health Service (NHS) in the UK and the newly introduced National Health Scheme (NHIS) in Nigeria. Other avenues include community health insurance schemes and private health insurance schemes.

\section{Limitations}

This study was not without limitations. First, the participants were not clustered by income/socioeconomic class; however, low-income individuals would be more impacted by the increase than high-income individuals. Price is a significant determinant of health care demand in many poor rural areas in developing countries such as Nigeria and price elasticity is higher for low-income than for high-income groups ${ }^{16}$. Second, while the price increase provides some aspects of a natural experiment, there is no control group, so that we cannot rule out the possibility that the observed change in use is not confounded by other factors. However, in order to limit the effect of confounders, we focused on changes right around the price change (i.e. 12 months before and 12 months after), since the further out from the price change, the more likely that other confounding factors come into play.

\section{Conclusion}

In comparison to reported PED on health care products this paper found a relatively high PED in psychiatric consultation following an increase in user fees for psychiatric consultation. The results of this study also provide some insights that can be applied in Nigeria to design successful health care financing strategies that puts patients' financial capability into consideration. We recommend further studies on Arc-PED for mental health services using data that lists weekly visit counts, weekly patient counts and weekly visits per patient before and after the price increase. This will help policy makers and other stakeholders to appreciate the different impacts of price change on visits change, patient change and visit/patient change, which will also better substantiate patients' adjustment to price increase.

\section{Implications for behavioral health}

This study suggests that an increase in consultation fees was associated with considerable reduction in mental health service use. Given that most payments for such services in Nigeria are made out- of - pocket, this was not unexpected. The findings suggest a need for greater sensitivity to these issues on the part of hospital administrators, researchers, policymakers, treatment providers and the general public. Efforts should also be made to disseminate the findings of this study to the above listed stakeholders to reduce the likelihood of arbitrary increases in prices of health care services.

Funding: The study was fully sponsored by Oluyomi Esan

\section{Conflict of interest}

Oluyomi Esan declares that he has no conflict of interest.

\section{References}

1. Pettinger, T. Difference between Point and Arc Elas-

African Health Sciences Vol 16 Issue 4, December, 2016 
ticity of Demand. 2012 November 19, 2012 [cited 2015 August 8, 2015; Available from:http://www.economicshelp.org/blog/6260/economics/difference-between-point-and-arc-elasticity-of-demand/.

2. Liu, S. and D. Chollet, Price and Income Elasticity of the Demand for Health Insurance and Health Care Services: A Critical Review of the Literature. 2006, Mathematica Policy Research, Inc.: Washington, DC 20201.

3. Newhouse, J.P. and The Insurance Experiment Group, "Free for All? Lessons from the RAND Health Insurance Experiment. 1993: Havard University Press.

4. Lagarde, M. and N. Palmer, The impact of user fees on health service utilization in low- and middle-income countries: how strong is the evidence? Bull World Health Organ, 2008.86(11): p. 839-848.

5. Bennett, S., The impact of the increase in user fees: a preliminary investigation. Lesotho Epidemiol Bull, 1989. 4: p. 29-37.

6. Gertler. P, Locay. L, and Sanderson. W, Are user fees regressive? The welfare implications of health care financing proposals in Peru. J Econom 1987. 36: p. 67-88.

7. Yoder, R.A., Are people willing and able to pay for health services? Soc Sci Med, 1989. 29(1): p. 35-42.
8. Russell, S. and L. Gilson, User fee policies to promote health service access for the poor: a wolf in sheep's clothing? International Journal of Health Services, 1997. 27(2): p. 359-379.

9. The World Bank Group, World Development Indicators: Health systems. 2013.

10. National Population Commission Nigeria, National Census. 2006.

11. World Bank Institute, Basics of Health Economics, in Module 04 : The Nature Of Demand. 2013.

12. Central Intelligence Agency, CIA World Fact Book.

13. Saraceno, B. and C. Barbui, Poverty and Mental illness. Can J Psychiatry, 1997. 42(3): p. 285-90.

14. Vick, B., K. Jones, and S. Mitra, Poverty and severepsychiatric disorder in the U.S.: evidence from Medical Expenditure Panel Survey. J Ment Health Policy Econ, 2012. 15(2): p. 83-96.

15. Esan, O.B., L. Kola, and O. Gureje, Mental disorders and earnings: results from the Nigerian National Survey of Mental Health and Well-Being (NSMHW). J Ment Health Policy Econ, 2012. 15(2): p. 77-82.

16. Qian, D., et al., Determinants of health care demand in poor, rural China: the case of Gansu Province. Health Policy and Planning, 2009. 24(5): p. 324-334. 